\title{
James Matthews Duncan (1826-90) and the dynamics of labour
}

\author{
Peter M Dunn
}

James Matthews Duncan was born in Aberdeen in $1826,{ }^{1}$ the son of a shipping merchant. He was educated at the grammar school and at Marischal College in Aberdeen where he took a Master of Arts degree. Medical studies followed both there and in Edinburgh and Paris, and in 1846 at the age of 20 he obtained an Aberdeen doctorate of medicine.

While in Edinburgh he had come under the influence of Sir James Young Simpson, professor of midwifery, and so distinguished himself that after his graduation, was appointed as his assistant. One year later, Matthews Duncan played an important part with Simpson in the discovery of the anaesthetic properties of chloroform. Shortly afterwards, he began practice in Edinburgh, and in 1853 began a course of lectures on midwifery at the Extramural School. His lectures were both practical and scientific and he soon had an international reputation in obstetrics. He was elected Fellow of the Royal Society and Fellow of the Royal College of Physicians, Edinburgh, and in 1861 was appointed physician to the Royal Infirmary. He was also greatly instrumental in founding the Royal Hospital for Sick Children in Edinburgh (fig 1).

He delighted in research which he pursued with single-minded energy. His clinical instinct was intuitive and he rarely needed to retract anything he had written or said. Speaking fluent French and German, he was also widely read. It was he who coined the term "missed abortion" and he also described the method of placental separation. His memory was remarkable, his erudition encyclopaedic, and he was a prolific author. Besides his Clinical Lectures on Diseases in Women, his best known works include Researches into Puerperal Mortality, Fecundity, Fertility and Sterility, and Researches in Obstetrics and the Mechanism of Natural and Morbid Childbirth. ${ }^{2}$ The following extracts are taken from three essays on the dynamics of labour that were published in $1868 .^{2}$ They reveal just how far his enquiring mind was in advance of the times.

Perinatal Medicine and Child Health, University of Bristol, Southmead Hospital, Bristol BS10 5NB PM Dunn

Correspondence to: Professor PM Dunn.

\section{On the pelvic articulations in parturition}

"In the latter half of pregnancy the soft tissues contributing to form the pelvic joints are invariably, or almost invariably, found softened as if by serous infiltration; and the

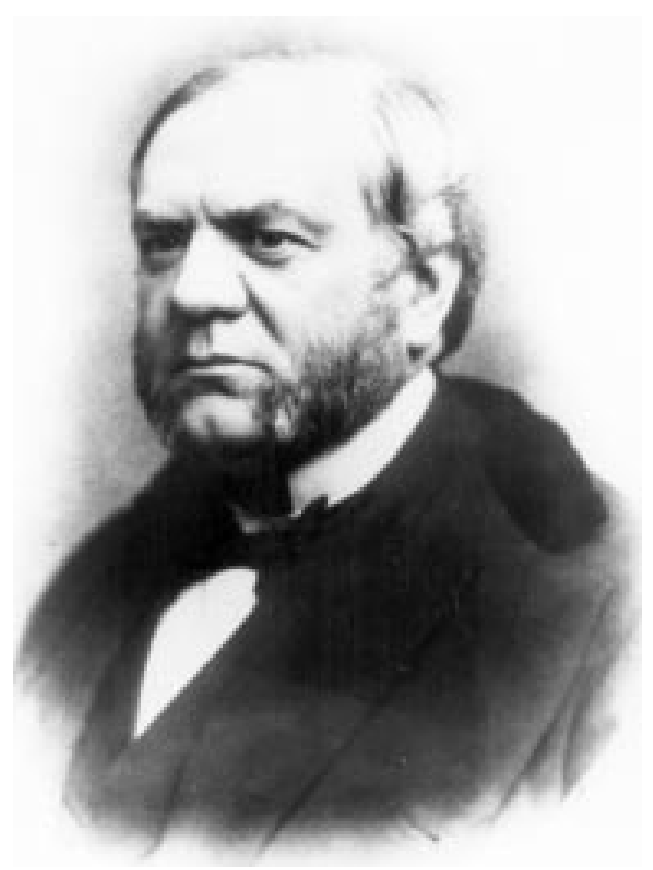

Figure 1 Dr Fames Matthews Duncan, 1826-90.

joints are consequently relaxed... The softening of these tissues is generally accompanied by their increase in thickness, a change which will in itself have, as a necessary consequence, the separation of the bones and the enlargement of the pelvic circle ... in the latter part of pregnancy, we can, without difficulty, assert that at that time the pelvic bones enjoy freer and more extensive movements than at other times ... in the erect position the brim of the pelvis is in its enlarged condition, the symphysis pubis being then depressed, while the outlet is correspondingly contracted. Now in the course of the first stage of labour, while the head is pressing into the brim, the human female is generally standing, sitting, or lying on her back, or in an easy position. But as soon as the head has descended into the pelvis and impinged upon the sensitive vagina, then forcing efforts accompany the pains. These forcing efforts consist, in great part, of powerful contractions of the anterior abdominal muscles, the effect of which, especially the action of the two recti muscles, will be to tilt 
up the symphysis pubis, thus throwing the promontory forwards, contracting the brim, and enlarging the outlet, and diminishing the angle of inclination of the pelvis. To all these changes the position usually assumed by the female in the second stage of labour will contribute. For it has already been stated, that the simple bending of the body forwards has for its effect the tilting upwards of the apex of the sacrum and enlarging of the outlet. And it is a curious fact, that a woman in her forcing pains, in the second stage, is found to draw up her legs, and bend her body forwards, thus inducing changes in her pelvis which facilitate the advance of the child in that stage."

\section{The power exerted in ordinary labours}

"The dynamics of natural labour have been the field of very little successful study or investigation. I purpose, first, to show what amount of pressure per square inch is sustained by the ovum in the easiest class of natural labours, and thence to estimate the propelling power exerted in such cases ... the attentive observer of a series of easy natural labours has no difficulty in arriving at the conclusion, that in not a few cases the same force which ruptures the bag of membranes is able to, and actually does, complete the delivery. The strength of the membranes is thus shown to give us a means of ascertaining the power of labour in the easiest class of natural cases... The strength of the foetal membranes lies in the innermost sac, in the amniotic membrane, which appears the thinnest and most delicate of all. To try the strength of it, as well as of the others, I made numerous experiments... The strongest membrane found in the experiments indicated, by the pressure required to burst it, an extruding force of $371 / 2 \mathrm{lbs}$. We may therefore, I think, safely venture to assert, as a highly probable conclusion, that the great majority of labours are completed by a propelling force not exceeding $40 \mathrm{lbs}$.

If we regard the figure of $4 \mathrm{lbs}$ given by Poppel as equal to the power exerted in the easiest labour he has observed, or the corresponding figure of $6 \mathrm{lbs}$ according to my calculations, and keep in mind that the average weight of the adult foetus exceeds either of these weights, we are led to the conclusion that in the easiest labours almost no resistance is encountered by the child; that it glides into the world propelled by the smallest force capable of doing so; that, with the mother in a favourable position, the weight of the child is enough to bring it into the world -a result which many clinical facts at least appear to confirm.”

\section{The greatest power of labour exerted in difficult cases}

"I ... estimate the maximum expulsive power of labour (including the uterine contractions with the assistant expulsive efforts) as not exceeding $80 \mathrm{lbs}$.
At present, I can divine no method of arriving at an estimate of the expulsive power of labours generally except the following; and I must guard myself from being supposed to recommend its use, in the meantime at least. A fine tube, filled with water and of resisting material, may be introduced into the small pool of liquor amnii which remains after the rupture of the membranes, filling up the spaces otherwise vacant on the anterior aspect of the foetus. This tube should be provided with an aperture at its uterine end; it should be curved, so that when introduced it may lie easily in the pelvis, occupying the least possible space, so that no unnecessary resistance be offered to the advance of the foetus; its wall should taper to either side, a cross section of it having a long pointed fusiform outline, in order that its presence may not produce on either side of it a channel for the running off of the pool of liquor amnii; lastly, its external end should be in communication with a column of mercury in a vertical tube, enclosing a column of air under only ordinary barometrical pressure. During the pains the rise of the mercury in the tube may be measured, and calculations from these measurements might be made, identical with those already given in the former chapter of this part. By this means, if successfully applied, the force of any labour may be exactly known. And it is scarcely necessary even to suggest how immeasurably valuable to the accoucheur such an estimate would be, substituting, as it would, an experimentally accurate statement of great importance for the vague notions at present relied on, even when the wisest and most experienced practitioner lends his counsel ... when a case is protracted, to have a means of estimating the pressure exerted on the child and maternal passages; when, in any case, instrumental interference is under consideration, to have a means of judging if the error is in the force exerted or in the resistance, etc. etc. That some means of thus increasing the beneficent power of the accoucheur will be discovered, I confidently anticipate."

Matthews Duncan was of middle height, powerfully built, and with a firm upright carriage. His face was generally impassive but capable of great expression. In manner he was modest, plainspoken, and honest. With patients he was kind, sympathetic, and attentive, and was never hurried or wearied by their problems. He had no hobbies apart from his family, his friends and a love of his native countryside. In 1860 he married Jane Hotchkiss and together they had 13 children. Family holidays were spent in Scotland, where free from the cares of practice, he was a rich source of jokes and anecdote.

On the death of Sir James Simpson in 1870 it was generally expected that Matthews Duncan would assume his mantle. However, his name was passed over, and when a little later he was invited to become obstetric physician to $\mathrm{St}$ Bartholomew's Hospital, he moved to London. There he rapidly became recognised as the leading obstetric authority of his day. His prac- 
tice flourished as it had in Edinburgh. Many honours came his way, including the FRS and FRCP of London, LLDs of Edinburgh and Cambridge, and an honoury MD from the University of Dublin. He was made an honorary member of the main medical societies of America, Russia, Austria, Germany and Norway.

At the age of 60 he retired from obstetrics. Two years later, in 1890, he developed angina pectoris and travelled to Baden-Baden to recu- perate. There he suffered a severe heart attack and died shortly afterwards. Mourned by many, he was buried at Finchley. Queen Victoria expressed her feelings in a telegram to his widow in which she wrote: "The Country and Europe at large have lost one of their most distinguished men, and one who will be sorely missed."

1 Anonymous. Obituary: James Matthews Duncan, M.D., F.R.S. Lancet 1890; ii: 594-6.

2 Duncan JM. Researches in Obstetrics. Edinburgh: A \& C Black, 1868 . 